\title{
O JOGO EXISTENCIAL E A RITUALIZAÇÃO DA MORTE ${ }^{1}$
}

Bellato R, Carvalho EC. O jogo existencial e a ritualização da morte. Rev Latino-am Enfermagem 2005 janeiro-fevereiro; 13(1):99-104.

Esta reflexão aborda o medo da morte que acompanha o existir humano desde o seu alvorecer, sendo o ser humano o único ser vivo que sabe que vai morrer, o que o leva a antecipar esse medo, fazendo-o companheiro de toda sua vida. Para diminuir essa "angústia mortal" tem ele tido, ao longo dos tempos, que "negociar" com a morte, como maneira de enfrentamento desse medo. Essa compreensão se torna importante por sermos profissionais da enfermagem, que cuidamos, no nosso quotidiano de trabalho, do ser humano em processo de morrer.

DESCRITORES: morte; enfermagem; atitude frente à morte

\section{THE EXISTENTIAL GAME AND THE RITUALIZATION OF DEATH}

This reflection approaches the fear of death that has accompanied human existence from its dawn. Humans are the only living beings who know about death, which makes them anticipate this fear by turning it into a companion for life. In order to reduce this "deadly anguish", mankind has had to negotiate with death over time, as a way of confronting this fear. This understanding becomes important since we are nursing professionals who, in our daily work, deliver care to the human being in the process of dying.

DESCRIPTORS: death; nursing; attitude towards death

\section{EL JUEGO EXISTENTIAL Y LA RITUALIZACIÓN DE LA MUERTE}

Esta reflexión discute el miedo de la muerte que acompaña el existir humano, siendo el ser humano el único ser vivo que sabe que se va a morir, lo que le lleva a anticipar ese miedo, haciéndolo un compañero en toda su vida. Para disminuir esa "angustia mortal", el hombre negocia con la muerte, como manera de enfrentar tal miedo. Esa comprensión se hace importante para los profesionales de la enfermería, que en su trabajo cotidiano cuidan del ser humano en el proceso de morir.

DESCRIPTORES: muerte; enfermería; actitud ante la muerte

\footnotetext{
${ }^{1}$ Trabalho extraído da tese apresentada à Escola de Enfermagem de Ribeirão Preto, da Universidade de São Paulo; ${ }^{2}$ Doutor em Enfermagem, Professor Adjunto da Faculdade de Enfermagem da Universidade Federal de Mato Grosso, e-mail: roseney@terra.com.br; ${ }^{3}$ Doutor em Enfermagem, Orientador, Professor Titular da Escola de Enfermagem de Ribeirão Preto, da Universidade de São Paulo, Centro Colaborador da OMS para o desenvolvimento da pesquisa em enfermagem
} 


\section{ALGUMAS CONSIDERAÇÕES INICIAIS}

A reflexão que aqui fazemos busca trazer alguns elementos que possam subsidiar a compreensão mais ampla acerca da morte como um dado antropológico, cuja presença tem sido motivo de angústia para o ser humano ao longo de sua existência, expondo-lhe, inexoravelmente, sua vulnerabilidade de ser mortal. Nós, humanos, como todos os seres vivos marcados pela temporalidade da vida, lutamos contra a idéia de nossa finitude, sendo que temos buscado 0 alívio possível para o paradoxo existencial que se apresenta frente ao dualismo vida e morte. Tal paradoxo tem sido marcante na cultura ocidental e agudiza, sobremaneira, essa angústia, tornando mais difícil o seu enfrentamento, visto que colocamos em situação de oposição esses dois momentos de uma mesma realidade: a de sermos seres vivos e que, portanto, iremos morrer um dia.

Ao aprofundarmos nossa compreensão quanto às estratégias de enfrentamento da angústia que a consciência da sua finitude tem provocado no ser humano ao longo dos tempos, amparamo-nos em alguns estudiosos do tema dentro da Sociologia e da Antropologia, particularmente na vertente francesa. Essa compreensão se torna importante para a enfermagem visto que lidamos com a morte em nosso quotidiano de trabalho, tanto como realidade em si, no cuidado àquele que se encontra em processo de morte e de morrer bem como à sua família, quanto na possibilidade de morte próxima que permeia 0 imaginário de qualquer pessoa que vivencia um processo de doença.

Nossa incapacidade de dar àqueles que morrem a ajuda e afeição de que mais que nunca precisam, quando se despedem dos outros seres humanos, se dá exatamente porque a morte do outro é uma lembrança de nossa própria morte. A visão da pessoa que vivencia seu processo de morte e de morrer abala as fantasias defensivas que as pessoas constroem como uma muralha contra a idéia de sua própria morte ${ }^{(1)}$. Assim, entender tais mecanismos defensivos se torna de grande importância para os profissionais da saúde e da enfermagem, de maneira que possam compreender os sentimentos e atender as necessidades daquele que vivencia o seu processo de morte e de morrer, proporcionando-lhe o conforto que a sensação de pertencimento e a afeição podem oferecer.

\section{O MEDO DA MORTE E O SEU ENFRENTAMENTO PELO SER HUMANO ATRAVÉS DOS TEMPOS}

As sociedades primitivas

O jogo existencial do ser humano, do qual vida e morte se fazem parceiras inseparáveis, é um problema dos vivos e, apenas e tão somente, dos vivos humanos, pois, embora compartilhem 0 nascimento, a doença, a juventude, a maturidade, a velhice e a morte com os animais, apenas os seres humanos, dentre todos os seres vivos, sabem que morrerão ${ }^{(1)}$. Assim, a imagem da morte tem acompanhado o existir humano desde seu alvorecer, abrindo enorme vazio diante da vida, representado por um aterrorizante não-ser inominável. Amorte, porém, nunca deve ser entendida como experiência real do sujeito ou de um corpo, mas, eventualmente, como na forma de uma relação social na qual se perde a determinação do sujeito e do valor $^{(2)}$. Mas, se a morte se apresenta como um vivido impossível, a experiência simbólica da morte não se faz menos angustiante. Como permanência antropológica, tem tido o ser humano, ao longo dos tempos, que negociar com essa morte, no sentido de diminuir a angústia mortal dessa ausência/presença, ruptura/continuidade, promoção/destruição que é o morrer ${ }^{(3)}$.

Dentro dessa perspectiva, a ritualização mítica da morte tem tido a função de transcender o sofrimento pela finitude do ser humano, pois, desde tempos imemoriais, o dado primeiro, fundamental e universal da morte humana é a sepultura, mostrando assim que é isso o que nos assegura nossa 'humanidade' em relação aos demais animais. A morte sempre suscitou emoções que se socializaram em práticas fúnebres, e o não-abandono dos mortos implica uma crença na sua sobrevivência, não existindo praticamente qualquer grupo, por muito 'primitivo' que seja, que abandone os seus mortos ou que os abandone sem ritos. Esses ritos trazem a imagem de 'passagem' para um outro estágio, sempre como metáfora de prolongamento da vida, seja ela através de um sono, uma viagem, um nascimento, uma doença, seja através de uma entrada para a morada dos antepassados. Projeta-se, assim, a vida para um tempo indefinido, mas não necessariamente eterno ${ }^{(4)}$.

Com isso o morto ganha status especial, pois reconhece-se que ele já não é um vivo vulgar. Essa mudança de estado do morto, no entanto, não deixa de provocar profundas perturbações no círculo dos vivos, que serão ritualizadas, coletivamente, nas cerimônias fúnebres. Os rituais fúnebres têm também a função de fazer o morto completar a viagem para o seu território definitivo, protegendo, dessa forma, a comunidade contra o seu retorno ${ }^{(5)}$.

No entanto, a morte nas sociedades primitivas não era personalizada, ou seja, dava-se como resultado de uma intervenção maléfica externa, que poderia ser um feitiço ou obra de um ancestral que voltou para buscar um membro da comunidade. A presença obsessiva da morte e do morto na mentalidade de povos primitivos se mostra pela presença dos "espíritos", isto é, dos mortos, em toda a vida quotidiana, regendo a caça, a guerra, as colheitas, as chuvas, etc. ${ }^{(4)}$.

Também o horror da decomposição do cadáver suscita rituais para abrandá-lo e, na pré-história, foram criadas algumas práticas que visavam apressar a decomposição (cremação e canibalismo), evitá-la (embalsamento) ou afastá-la do convívio com os vivos (sepultamento, transporte do corpo para um local ritualístico). Se essa presença pútrida 
do morto sempre foi sentida como contagiosa, muitas das práticas funerárias e pós-funerárias visam proteger os vivos do espectro maléfico ligado ao cadáver que apodrece. Os rituais do luto têm o sentido da purificação, sendo seu período correspondente à duração da decomposição. É preciso lembrar ainda que a impureza trazida pela putrefação afeta também os parentes do morto, sendo eles obrigados a se cobrirem com um sinal distintivo ou esconder-se, durante o período no qual grassa o 'contágio da morte ${ }^{,(4)}$.

É preciso lembrar que o 'horror da morte', esse fantasma que sempre acompanhou o ser humano, e que se traduz pela dor do funeral, pelo terror da decomposição do cadáver e pela obsessão da morte, tem por denominador comum a 'perda da individualidade'. Essa dor pela perda será tanto maior quanto mais próximo ou significativo for o morto para a família ou a comunidade. Portanto, não é o fenômeno da putrefação em si que traz o terror, mas a emoção, o sentimento ou a consciência da perda da individualidade, quando o morto não está individualizado, isto é, não reconhecido como ser humano, tal como o inimigo ou o traidor privados de sepultura, existe, diante da podridão, apenas indiferença e simples mal cheiro ${ }^{(4)}$. E a revelação da morte do outro, causada pela presença dos "restos" (o cadáver), faz com que 0 ser humano apreenda a essência da existência mortal, ou seja, a noção da sua finitude, pois a morte ganha corpo e rosto, ela se encarna na carne do cadáver ${ }^{(3)}$.

O 'complexo da perda da individualidade' é um complexo traumático, levando ao 'traumatismo da morte', isto é, "toda distância que separa a consciência da morte da aspiração à imortalidade, toda a contradição que opõe o fato brutal da morte à afirmação da sobrevivência"(4). Daí deriva que a violência do traumatismo provocado por aquilo que nega a individualidade implica em afirmação não menos intensa da individualidade, quer seja a nossa própria morte quer seja a do ente querido ou próximo. Aindividualidade que se revolta contra a morte é uma individualidade que se afirma sobre a morte, ou seja, que concebe a sua própria imortalidade. Essa 'consciência humana da morte', no entanto, não se baseia no desconhecimento da realidade biológica, mas no seu reconhecimento, assim como não significa cegueira ante a morte, mas a sua lucidez. Essa lucidez não é, porém, tomada de consciência do conhecimento específico, mas sim um conhecimento propriamente individual: uma apropriação da consciência, visto que a consciência da morte não é algo inato, antes um produto de uma consciência que compreende o real ${ }^{(4)}$.

Ao mudar de status, passando de pessoa viva para ancestral morto, esse perde sua individualidade, ganhando, porém, sua reidentificação dentro de uma categoria arquetípica. Chega-se, assim, à crença na imortalidade, que seria a dialética resultante da consciência da morte e do traumatismo da morte, que se reforçam mutuamente ${ }^{(6)}$. preciso salientar que, em todas as sociedades, desde as mais primitivas até a atualidade, o ser humano sempre teve, efetivamente, dois tipos de morte: uma biológica, que representa o fim do organismo humano, e uma morte social, que representa o fim da identidade social do indivíduo. Essa última ocorre em um processo que compreende uma série de cerimônias, incluindo aí o funeral, no qual a sociedade oficializa e ritualiza a despedida de um dos seus e reafirma sua continuidade sem ele ${ }^{(7)}$.

É essa compreensão, característica própria do humano e implícita desde a pré-história que, longe de se refletir em aceitação, leva o ser humano a revoltar-se contra sua inelutável finitude, ávido de uma imortalidade que desejaria realizar. Se não buscasse alguma forma de adaptação à morte, o ser humano "morreria de morrer"(4), visto que, a idéia obsedante da morte como fim último e sem qualquer termo de continuação posterior, Ihe seria mortal. O paradoxo adaptação/ inadaptação à morte é expresso nos rituais funerais e de luto, ou seja, o luto expressa socialmente a inadaptação individual à morte, mas, ao mesmo tempo, é o processo de adaptação social que tende a fazer cicatrizar a ferida dos indivíduos que sobrevivem ${ }^{(4)}$.

Mas, para onde vão os mortos após a morte? Também aí impera o paradoxo humano de querer o morto, agora transformado em espírito, ao mesmo tempo perto e longe dos vivos. Desde as camadas mais antigas das crenças, os mortos habitam o espaço próximo do grupo a que pertenciam. Mesmo nas civilizações que, por temor dos mortos, afastaram um pouco as tumbas das habitações dos vivos, continuam aí localizados, quer seja por meio de uma ossada simbólica (o crânio, por exemplo), quer por meio de um substitutivo figurativo (bonecos de madeira ou, nos casos atuais, fotografias dos ausentes queridos). Com essa forma de agir conciliam-se os contraditórios desejos dos vivos: conservar o morto (para que não se irrite e para que os proteja) e, ao mesmo tempo, evitar sua presença macabra ${ }^{(4)}$.

Dentro da perspectiva de um tempo linear, a morte é tida como perda, ruptura, ausência. Porém, a lógica da vida é afirmação de continuação e de plenitude. Há, pois, que se ultrapassar a dialética da cisão vida-morte, buscando vencer o horror da finitude, inventando, para além da racionalidade, correspondências entre o mundo dos vivos e o mundo dos mortos. Essa correspondência, aparentemente mais eficaz em outros tempos, era vivida coletivamente, não constituindo, portanto, um drama pessoal, mas sendo largamente negociada no seio da sociedade. Assim, a ampla ritualização da morte que essas sociedades empreendiam, consistia numa estratégia global do ser humano contra a Natureza, procurando domar sua selvageria e violência ${ }^{(8)}$. E se 0 ser humano de antigamente temia a morte, angustiava-se diante dela, no entanto, tal temor e angústia eram tranqüilamente traduzidos em palavras e canalizados para ritos familiares e sociais. Justamente por isso, a morte não passava o limite do indizível, do inexprimível, a ponto de o ser humano dela se afastar, de fugir, de proceder como se ela não existisse, ou de falsificar sua aparência.

Vale ressaltar que nessas sociedades primitivas morria-se 
sempre em público, pois nunca se estava só, fisicamente, no momento da morte. Elas construíam, portanto, sistemas de defesa contra a angústia da morte, embasados em ritos e crenças que buscavam dar ao ser humano ilusão de perenidade e, por não se apoiarem na individualização e sim na participação da pessoa no seio do grupo, não concebiam a morte como ausência ou separação irreparáveis ${ }^{(9)}$.

\section{A Idade Média e a Idade Moderna}

Essa troca social entre o mundo dos vivos e o mundo dos mortos tende, aos poucos, a se desfazer. Se os ritos de morte eram comunitários até o século XIII, uma vez que a Igreja Católica intervinha, até então, apenas para absolver o moribundo ou o morto dos seus pecados, a morte passou a ser, a partir de então e durante muito tempo, 'clericalizada'. Os ritos que tendiam a exprimir a violência da dor, passaram a representar o controle de si, com a família e os amigos silenciados no seu drama. O padre passou a ocupar a cena principal, e não mais o morto. Após o último suspiro, o morto não pertence mais nem aos seus pares ou companheiros, nem à família, mas à Igreja ${ }^{(9)}$.

Concomitantemente a essa clericalização da morte, o corpo do morto, que era considerado figura familiar pelos ritos de morte que Ihe votavam os vivos, passa a ser insuportável à vista, levando à sua ocultação, primeiro através da mortalha e, posteriormente, através do esquife. Além disso, se nas sociedades tradicionais a afetividade era repartida entre um número maior de pessoas, não se restringindo, portanto, apenas aos membros próximos da família, mas se diluindo em círculos cada vez mais amplos, a partir do século XVIII, a afetividade é, bem ao contrário, inteiramente concentrada, desde a infância, sobre algumas poucas pessoas que se tornam insubstituíveis e inseparáveis ${ }^{(9)}$. E tanto a repulsa pela figura da morte, como a afeição que é votada ao moribundo pela sua família, faz com que lhe ocultem a verdade do seu fim próximo, num silêncio que constrange tanto aqueles que o impõem como aquele que se vê alvo dele. E essa mentira, da qual são cúmplices tanto o moribundo como aqueles que desejam 'protegê-lo' da trágica notícia, empurra a morte para a clandestinidade.

Do século XX até nossos dias

Mas, se desde a Alta Idade Média até a metade do século XIX, a atitude diante da morte mudou, essa mudança deu-se, no entanto, de forma bastante lenta, se comparada com a revolução brutal das idéias e sentimentos observados a partir de então ${ }^{(9)}$. A morte, tão presente no passado, de tão familiar, vai se apagar e desaparecer, tornado-se vergonhosa e, por isso, objeto de interdição. Espetáculo nauseabundo, pelos odores e imagens que traz, torna-se inconveniente e, portanto, indecente a sua demonstração pública. Com isso, "uma nova imagem da morte vai se formando: a morte feia e escondida, e escondida porque é feia e suja"(10) ${ }^{(10}$. ritos de morte, que até então se mantiveram com algumas poucas modificações ao longo dos tempos, começam a ser esvaziados em sua carga mítica com os processos empregados para o seu escamoteamento.

Processo concomitante e profundamente imbricado se dá no sentido de extrair da morte as armas que, se acredita, defenderão a vida de seu ataque mórbido. A medicina desnuda a morte buscando munir-se, através dela, de conhecimentos e técnicas para ludibriar ou, pelo menos, adiar a finitude humana. Assim, morrer de velhice passa a ser considerada a forma natural de morte. Por conseqüência, todas as outras maneiras de se morrer são consideradas contra a natureza e, por isso, mortes desnecessárias. Com isso, aos poucos, 0 conhecimento médico foi negando e se desvencilhando do 'obscurantismo' trazido pela idéia mágico-sobrenatural da morte, criando um halo de poder em torno de si e tomando o lugar da divindade destronada.

\section{DO MACABRO AO MÓRBIDO - A MEDICINA ENTRA EM CENA PARA ENFRENTAR A MORTE}

A antropológica carga mítica que a morte sempre representou na história humana, e que era ritualizada através da 'troca' entre 0 mundo dos vivos e dos mortos, não podendo mais ser tão intensamente 'negociada' simbolicamente no bojo da dimensão sobrenatural, faz com que o ser humano busque novas formas de diminuir a angústia diante da sua finitude implacável. E, se os sacerdotes e feiticeiros, dos tempos idos, faziam a ligação entre esses dois mundos, procurando sensibilizar as entidades sobrenaturais quanto ao sofrimento humano e à morte, solicitando sua benevolência para abreviá-los, a medicina traz uma nova geração de sacerdotes/feiticeiros que se colocam frente à deusaciência, buscando seu poder de maneira a prolongar a vida, colocando em suspenso a morte.

Assim, tanto a repulsa pela morte como os conhecimentos adquiridos para o seu adiamento indefinido por parte da medicina, legitimaram a passagem do quarto do moribundo da sua casa para o hospital. Esse passou a ser o templo da morte solitária. Apenas os parentes mais próximos acompanham, a uma distância segura, o findar, não raro longo e silencioso, do ente querido. Chega ao fim a morte solene e circunstanciada, em família: morre-se no hospital, símbolo da extraterritorialidade da morte. Sendo a morte considerada obscena e embaraçosa, nada pode deixar de vestígio. E o imenso dinamismo mortuário já não é da ordem da piedade, é o próprio signo do desamparo ${ }^{(2)}$.

Com isso, abolimos o 'macabro' de nossa existência, colocando em seu lugar o 'mórbido', que nada mais é do que uma forma rarefeita de vida que se extenua no longo trajeto para o vazio da 
morte. A sociedade ocidental, ciosa ante a acumulação de bens, acelerou o processo de individualização, abandonando o ser humano a seus fantasmas mortíferos. Mais do que nunca, ele se vê, dolorosamente, perante a morte, àquela do próximo e a sua própria. Não podendo dela escapar, ele a recusa; não podendo evitá-la, tornase dela instrumento. Essa sociedade que tanto horror tem da morte, não fazendo mais que desprezar a vida, ainda que proclame o contrário, acarreta sua própria morte ${ }^{(11)}$.

No consumo da sua própria morte, o ser humano se vê, contemporaneamente, diante de um paradoxo: ou assume a atitude do interdito, que consiste em fazer como se a morte não existisse, expulsando-a para fora da vida quotidiana, ou a aceita como um fato técnico, reduzindo-a ao estado de uma coisa qualquer, tão insignificante como necessária. Qualquer que seja a atitude, no entanto, não somente cada passo da vida a aproxima da hora da morte, como também é ela modelada pela morte, que é um elemento real da vida ${ }^{(12)}$. Nossa concepção da vida e nossa concepção da morte não são nada mais do que dois aspectos de um único e mesmo comportamento fundamental. A vida para lutar contra a morte tem necessidade de integrá-la no mais íntimo dela mesma. Escamotear a morte é o mesmo que se recusar a crer que a trazemos em nós, não como enfermidade ou punição, mas como lei necessária da vida da qual ela assume a riqueza e a renovação ${ }^{(13)}$.

\section{CONSIDERAÇÕES FINAIS}

Buscamos aqui traçar, a largos passos, a história do enfrentamento do medo da morte que o ser humano vem empreendendo ao longo dos tempos, tendo por foco a civilização ocidental. Esse enfrentamento tem se transfigurado em escamoteamento, da negação: o velório, feito em ambiente próprio e não mais em casa, se apresenta como um momento pouco compartilhado socialmente, onde as manifestações de tristeza e choro são contidas para não constranger os presentes, os cemitérios mais se parecem com jardins, o período de luto se resume a poucos dias, sendo que logo a vida da família do morto 'volta ao normal'.

Mesmo no hospital, territorialidade permitida para a morte, morre-se às escondidas, o morto parte na ponta dos pés. A equipe de saúde procura dissimular a presença da morte impedindo que as pessoas tenham acesso ao quarto daquele que morre, ainda que sejam parentes próximos, procurando fazer rapidamente o preparo do corpo e legalizando o novo status social do morto através da emissão do atestado de óbito. Até mesmo as palavras são denunciadoras dessa ocultação: evita-se dizer que alguém morreu, usando, em seu lugar, a expressão impessoal, e por isso mesmo menos angustiante, "foi a óbito".
É necessário compreender, no entanto, que nossa formação como enfermeiros e profissionais integrantes da equipe de saúde tem se dado no sentido de estarmos preparados, essencialmente, para a promoção e preservação da vida e, nesse contexto, entendemos a morte como algo contrário e não como parte intrínseca dela. A obstinação terapêutica leva até as últimas conseqüências a tentativa de afastar a morte e, nessa tentativa de afastamento indefinido, o doente não morre mais na sua hora, mas naquela da equipe de saúde. Como conseqüência última desse processo, temos a desumanização do atendimento àquele que morre, pois "a técnica matou a morte natural e o morrer dissolveu-se em um contexto sócio-organizacional no qual o funcional substituiu o humano. Por fim, a escamoteação da morte se faz expropriação e destituição, pois é tudo previsto para que o moribundo deixe de estar no centro de seu trespasse"(13).

Resgatar o humano dentro do processo de morte e do morrer, embora essencial à perspectiva do cuidado à pessoa e não apenas ao corpo biológico, não se apresenta como tarefa fácil, visto que nossa humanidade de "profissionais da saúde" e, portanto, da vida, se ressente desse enfrentamento, temendo olhar-se no espelho da própria finitude.

Iniciamos, porém, os primeiros passos nessa direção, embora ainda muito nos falte para caminhar. Temos visto numerosos estudos de enfermeiros que buscam questionar, já desde a formação, 0 posicionamento profissional frente ao ser humano que vivencia seu processo de morte e de morrer, assim como aos seus familiares. Nesse buscar por restituir a humanidade à morte, o espaço doméstico volta a ser pensado como local próprio para a vivência dessa experiência íntima e única na vida de cada ser humano, ainda que acompanhada do cuidado profissional. Tem sido objeto de reflexão também, sob diversos enfoques filosóficos, se o prolongamento biológico da vida de maneira artificial e indefinida é eticamente aceitável. Indagações são feitas, por fim, sobre como podemos enfrentar o nosso próprio medo da morte e, assim, nos colocarmos de maneira mais próxima diante do outro ser humano que enfrenta a experiência única de estar findando sua existência física.

Tais questões, de profundo cunho antropológico, envolvem um reposicionamento do ser humano diante da morte e, por serem os aspectos aqui apresentados resultado da construção históricosociocultural própria do Ocidente, precisam ser debatidas no seio da sociedade e não apenas na internalidade de um segmento profissional. No entanto, para que nós, profissionais da enfermagem, que lidamos quotidianamente com o processo de morte e do morrer do outro, possamos apreender o que esse processo significa, faz-se necessário caminharmos em direção à nossa própria humanidade e procuramos entender o que ela traz em seu bojo para então, e só então, postarmonos humanamente como profissionais que cuidam. Talvez isso nos leve à compreensão de que a morte em si, na maioria das vezes, não é o grande problema para aquele que morre, mas sim o sentimento de 
desesperança, de desamparo e de isolamento que a acompanha, nascido do medo que as outras pessoas têm de enfrentar a certeza da sua própria morte ${ }^{(14)}$.

Nossa atitude diante daquele que enfrenta seu processo de morte e de morrer tem sido, paradoxalmente, a de abandoná-lo à sua angustiante solidão ou a de nos esforçarmos, ao máximo, por prolongar indefinidamente sua situação dúbia de quase-vivo ou de quase-morto, graças ao aparato tecnológico hoje disponível na área da saúde. No entanto, em ambas as posições o aspecto humano do morrer corre 0 risco de ser ocultado ou remetido para um segundo plano, juntamente com a pessoa que o vivencia. Essa reflexão se torna fundamental para a nossa própria 'condição humana', visto precisarmos assegurar àquele que morre seu justo lugar nesse processo. É necessário lembrar, por fim, que a morte não é um elemento puramente empírico de nossa experiência; a orientação para a morte é essencialmente implicada na experiência de toda a vida e de nossa própria vida ${ }^{(13)}$.

\section{REFERÊNCIAS BIBLIOGRÁFICAS}

1. Elias N. A solidão dos moribundos. Rio de Janeiro (RJ): Jorge Zahar; 2001.

2. Baudrillard J. As trocas simbólicas e a morte. São Paulo (SP): Loyola; 1996.

3. Thomas L-V. Antrhopologie de la mort. Paris (FR): Payot; 1975. 4. Morin E. O homem e a morte. Portugal (PT): Biblioteca Universitária; 1978.

5. Zaidhaft S. Morte e formação médica. Rio de Janeiro (RJ): Francisco Alves; 1990.

6. Eliade M. Mito do eterno retorno. São Paulo (SP): Mercuryo; 1992.

7. Helman CG. Saúde, cultura e doença. Porto Alegre (RS): Artes Médicas; 1994.

8. Thomas L-V. Mort et vie quotidienne. Cahiers Internationaux de Sociologie 1983 jun; 75:83-96.

9. Ariès P. O homem perante a morte. Portugal (PT): Biblioteca Universitária; 1979.

10. Ariès P. A história da morte no ocidente. Rio de Janeiro (RJ): Francisco Alves; 1977.

11. Foucault M. O nascimento da clínica. $5^{\mathrm{a}}$ ed. Rio de Janeiro (RJ): Forense-Universitária; 1998.

12. Simmel G. La tragedie de la culture et autre essais. Paris (FR): Rivage; 1988.

13. Thomas L-V. Les chairs de la mort. Paris (FR): Sanofi-Sinthélabo; 2000.

14. Kubler-Ross E. Sobre a morte e o morrer. $8^{a}$ ed. São Paulo (SP): Martins Fontes; 2000. 